\title{
Complex Production Structures in Assembly Processes
}

\author{
W. Grzechca, Member, IACSIT
}

\begin{abstract}
Product modularity has become an important issue. It allows producing different products through combination of standard components. One of the characteristics of modular products is that they share the same assembly structure for many assembly operations. The special structure of modular products provides challenges and opportunities for operational design of assembly lines. In this paper, an approach for design of assembly lines for modular products is proposed. This approach divides the assembly line into two parts: a subassembly line for basic assembly operations and a production structure for variant assembly operations. The design of the subassembly line for basic operations can be viewed as a single product assembly line balancing problem and be solved by existing line balancing methods. The subassembly line for the variant operations is designed as a job shop structure and is sequenced by priority heuristic methods. A final result of tasks assigning to the complex production structure is given and a quality of final solutions is discussed.
\end{abstract}

Index Terms-Assembly lines, heuristic methods, job shop structure, estimation of final results.

\section{ASSEMBly LiNE BALANCING PROBLEM}

Since always people created new items for their own needs and if these appeared to be helpful they tried both to improve them and manufacture them faster. In order to balance supply and demand the development of technology was a must. Definition of production can be therefore understood as transforming raw materials into a complete valuable product. This transformation combines various tasks of human work, automation and technology. It consists of steps after which the temporary product is closer to the final state. All these processes combined together define the assembly line which formal definition states: Industrial arrangement of machines, equipment, and workers for continuous flow of workpieces in mass-production operations. An assembly line is designed by determining the sequences of operations for manufacture of each component as well as the final product. Each movement of material is made as simple and short as possible, with no cross flow or backtracking. Work assignments, numbers of machines, and production rates are programmed so that all operations performed along the line are compatible. Automated assembly lines consist entirely of machines run by other machines and are used in such continuous-process industries as petroleum refining and chemical manufacture and in many modern engine plants. Although it does not seem difficult by the definition it is a complex field of research.

More than 100 years ago the idea of assembly line was introduced in Ford factory in Detroit. It was designed to be an

Manuscript received November 7, 2013; revised February 20, 2014

Waldemar Grzechca is with the Silesian University of Technology, 44-100 Gliwice, ul. Akademicka 2A, Poland (e-mail waldemar.grzechca@polsl.pl). efficient, highly productive way of manufacturing a particular product. Now in XXI century this way of assembly of final products is still very common and we can find it in many companies over the world. The basic assembly line consists of a set of workstations arranged in a linear fashion, with each station connected by a material handling device (transfer lines, roller conveyors, cranes et al.). The components are processed depending on set of tasks and they are performed at each station during a fixed period called as cycle time. The time it takes to complete a task at each workstation is known as the process time [1]. The cycle time of an assembly line is predetermined by a desired production rate. This production rate is set so that the desired amount of end product is produced within a certain time period [2]. In order for the assembly line to maintain a certain production rate, the sum of the processing times at each station must not exceed the stations' cycle time. If the sum of the processing times within a station is less than the cycle time, idle (delay) time is said to be present at that station [3]. One of the main issues concerning the development of an assembly line is how to arrange the tasks to be performed. The tasks are allocated to workstations according to known precedence relationships (very often in form of precedence graph) and specific restrictions which aim to optimize one or more objectives. A feasible assignment of tasks to workstations should guarantee that the following constraints: (1) each task must be assigned to exactly one workstation, (2) all precedence relationships among tasks must be satisfied and (3) the total process time of all the tasks assigned to a workstation cannot exceed the cycle time. The problem of assigning tasks to workstations in such a way that some objectives are optimized is called assembly line balancing problem - ALBP. We can recognize generally two types of ALBP - minimizing number of workstations for a given cycle time (TYPE 1 of ALBP) or minimizing the cycle time for a given number of workstations (TYPE 2 of ALBP). The assembly line balancing problem (ALBP) originated with the invention of the assembly line. Helgeson et al [4] were the first to propose the ALBP, and Salveson [5] was the first to publish the problem in its mathematical form. However, during the first forty years of the assembly line's existence, only trial-and-error methods were used to balance the lines. Since then, there have been numerous methods developed to solve the different forms of the ALBP. Salveson [5] provided the first mathematical attempt by solving the problem as a linear program. Gutjahr and Nemhauser [6] showed that the ALBP problem falls into the class of NP-hard combinatorial optimization problems. This means that an optimal solution is not guaranteed for problems of significant size. Therefore, heuristic methods have become the most popular techniques for solving the problem. But we should underline that many studies on assembly line including exact solution methods and heuristics have been reported in the literature. The detailed 
reviews of such studies are given by Baybars [2], Erel and Sarin [3], and Scholl and Becker [7]. In the literature assembly line is classified as: straight assembly line, assembly line with parallel stations, U-shaped assembly line or two-sided assembly line. Other classification takes into account number of products which are produced on the line (single model line, multi-model line and mixed-model line).

\section{ASSEMBLy LiNE STRUCTURES}

There exists also a classification regarding plant layout which is used to describe the arrangement of physical facilities in a production plant [8]. Five types of layout can be distinguished:

- serial lines,

- U-shaped lines,

- parallel lines,

- parallel stations,

- two-sided lines.

\section{A. Serial (Single) Lines}

This is a very basic layout of a flow line production system (Fig. 1). It is determined by the flow of materials. It is mostly used for small size products. These lines have several disadvantages:

- monotone work,

- sensibility due to failures,

- inflexibility due to changing demand rates.

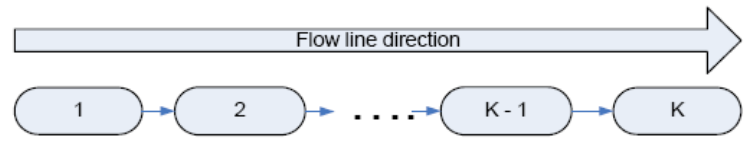

Fig. 1. Serial assembly line structure.

\section{B. U-Shaped Lines}

In order to deal with the problems of a serial line it was redesigned to a form of U-shape (Fig. 2). In such a line operators can work at more than one station simultaneously. For example first operator may both load and unload product units. As they are included in more tasks during production process they are gaining very important experience and enlarge horizons. It is very helpful in case of just-in-time production systems as it improves flexibility which is crucial in dynamically changing demand rates. What more, stations are closer together what results in better communication between operators and in case of emergency they are able to help each other effectively.

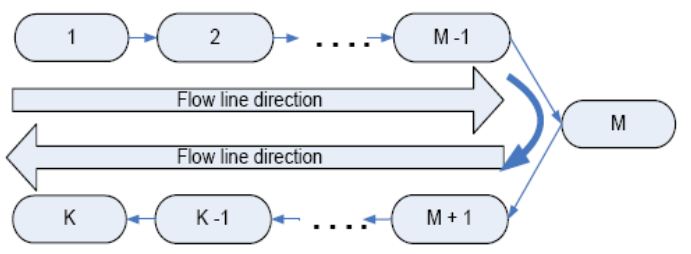

Fig. 2. U-Shaped assembly line structure.

\section{Parallel Lines}

In order to deal with problems described in case of a serial line it might be a good idea to create several lines doing the same or similar tasks (Fig. 3).

The advantages of such a solution [9], [10]:

- increased flexibility for mixed-model systems,
- flexibility due to changing demand rates,

- lowered risk of machine breakdown stopping the whole production,

- $\quad$ cycle time can be more flexibly chosen which leads to more feasible solutions.

The optimal number of lines is however a subject of discussion for every single case separately.

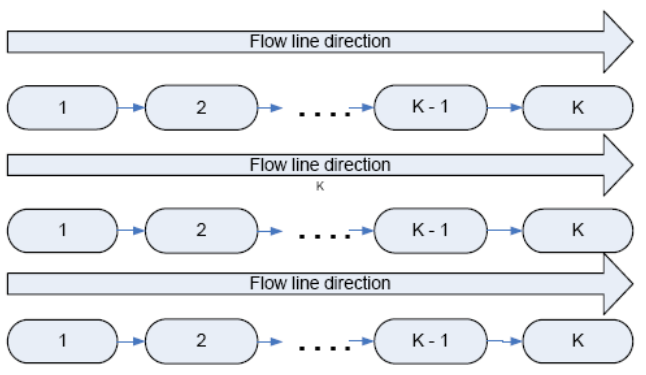

Fig. 3. Parallel assembly lines structures.

\section{Parallel Stations}

As an extension of serial lines bottlenecks are replaced with parallel stations (Fig. 4). Tasks performed on parallel stations are the same and throughput is this way increased [11]-[14].

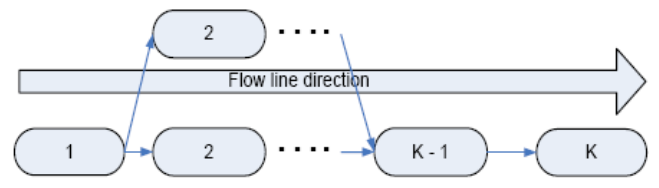

Fig. 4. Parallel stations

\section{E. Two-Sided Lines}

This kind of flow lines is mainly used in case of heavy workpieces when it is more convenient to operate on both sides of a workpiece rather than rotating it. Instead of single working-place, there are pairs of two directly facing stations such as 1 and 2 (Fig. 5) Such a solution makes the line much more flexible as the workpiece can be accessed either from left or right [15]-[19]. In comparison to serial lines:

- it can shorten the line length,

- reduce unnecessary work reaching to the other side of the workpiece.

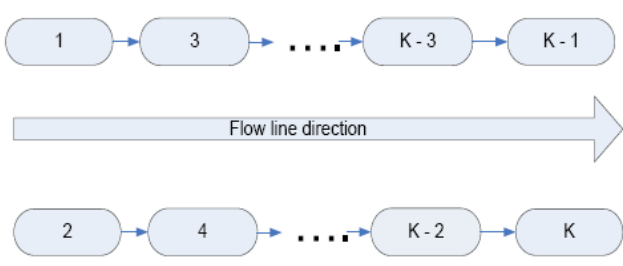

Fig. 5. Two - sided assembly line.

\section{FLOW AND JOB SHOP STRUCTURES}

In many manufacturing and assembly facilities each job has to undergo a series of operations. Often, these operations have to be done on all jobs in the same order implying that the jobs have to follow the same route. The machines are then assumed to be set up in series and the environment is referred to as a flow shop. The storage or buffer capacities in between successive machines may sometimes be, for all practical purposes, unlimited. When the routes are fixed, but not necessarily the same for each job, the structure is called job shop. In [20] a detailed description of complex structure of 
assembly line and flow shop structure is given. Authors developed an approach for designing production structure where modular components are assembled. In the next section of this paper a method of balancing and sequencing of complex system which includes assembly line structure and job shop structure is presented. In some companies when the products that are being processed are physically small or medium the production process is divided in two stages: first the tasks are handled in assembly line, then semi products are moved to buffers and in the second stage there are finished in job shop environment (Fig. 6). In some cases the production process starts first in job shop environment and then is finished in assembly line structure (Fig. 7). The two approaches will be discussed.

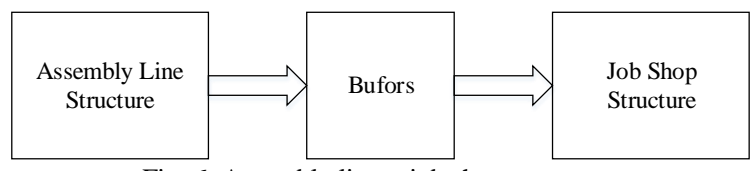

Fig. 6. Assembly line - job shop structure.

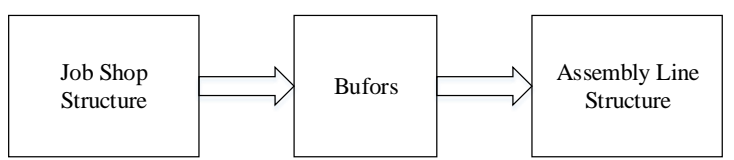

Fig. 7. Job shop - assembly line structure.

To obtain a balance of assembly line different heuristic methods are presented in the literature (Ranked Positional Weight method, Immediate Update First Fit methods which consider operations processing times, precedence graph with number of followers or predecessors, Hofmann Matrix method, Kilbridge \& Wester's method, etc.) [21]. In the next section the RPW method is considered. The ranked positional method was developed by Halgeson and Birnie [4]. This method assigns those jobs first whose followers have the largest total time. The positional weight of work element is its own processing time plus the processing time of all the following work elements. In RPW as stated earlier, the work element with the highest positional weight is selected and assigned to the current workstation. In job shop scheduling problem conflicts will probably occur. Therefore job shop scheduling based on priority (dispatches) rules. The most often used are: the shortest processing time (SPT), the longest processing time (LTP), first come first serve (FCFS), last come first serve (LCFS), the earliest due date (EDD), etc. A comprehensive survey of job shop scheduling techniques can be found in [22].

\section{Measures of Balance Quality}

Some measures of solution quality have appeared in line balancing problem. Below are presented three of them [2], [7].

Line efficiency (LE) shows the percentage utilization of the line. It is expressed as ratio of total station time to the cycle time multiplied by the number of workstations:

$$
L E=\frac{\sum_{i=1}^{K} S T_{i}}{c \cdot K} \cdot 100 \%
$$

where:

$K$ - total number of workstations,

$c$ - cycle time.

Smoothness index (SI) describes relative smoothness for a given assembly line balance. Perfect balance is indicated by smoothness index 0 . This index is calculated in the following manner:

$$
S I=\sqrt{\sum_{i=1}^{K}\left(S T_{\max }-S T_{i}\right)^{2}}
$$

where:

$S T_{\max }-$ maximum station time (in most cases cycle time), $S T_{i}$ - station time of station $i$.

Time of the line (LT) describes the period of time which is need for the product to be completed on an assembly line:

$$
L T=c \cdot(K-1)+T_{K}
$$

where:

$$
\begin{aligned}
& c \text { - cycle time, } \\
& K \text { - total number of workstations. } \\
& T_{k} \text { - load time of the last station }
\end{aligned}
$$

\section{NUMERICAL EXAMPLE}

We consider an example of manufacturing a final product in complex production system - single assembly line plus job shop system which consists of 3 machines (M1, M2, M3). In the second step we change the configuration: first we schedule job shop system of 3 machines and then we will finish our process in single assembly line. As an input data we know the precedence graph of our product (Fig. 8.) which is necessary for assembly line balancing calculations and the order of task in job shop system of 4 different variants of final products.

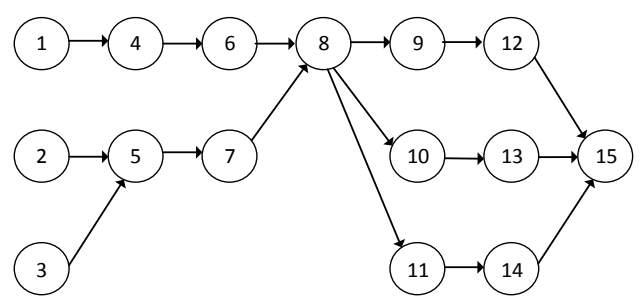

Fig. 8. Precedence graph of an illustrative example.

Below in Table I processing times of assembly operations are given. Table II consists of input data of job shop system.

TABLE I: PROCESSING TIMES OF ASSEMBLy OPERATIONS

\begin{tabular}{|c|c|c|c|c|c|}
\hline Task $\mathrm{i}$ & time & Task $\mathrm{i}$ & time & Task $\mathrm{i}$ & time \\
\hline 1 & 4 & 6 & 6 & 11 & 6 \\
\hline 2 & 3 & 7 & 4 & 12 & 7 \\
\hline 3 & 7 & 8 & 5 & 13 & 3 \\
\hline 4 & 2 & 9 & 3 & 14 & 1 \\
\hline 5 & 1 & 10 & 1 & 15 & 1 \\
\hline
\end{tabular}

TABLE II: INPUT DATA OF JOB SHOP STRUCTURE

\begin{tabular}{|c|l|}
\hline Variant $\mathrm{j}$ & \multicolumn{1}{c|}{ Order of operations } \\
\hline 1 & $\mathrm{M} 2(10)-\mathrm{M} 1(5)-\mathrm{M} 2(5)$ \\
\hline 2 & $\mathrm{M} 1(5)-\mathrm{M} 3(5)-\mathrm{M} 2(10)-\mathrm{M} 1(5)$ \\
\hline 3 & $\mathrm{M} 2(10)-\mathrm{M} 3(10)$ \\
\hline 4 & $\mathrm{M} 1(5)-\mathrm{M} 2(5)-\mathrm{M} 3(10)$ \\
\hline
\end{tabular}


The goal of our calculations is the find a feasible assignment of our tasks in assembly line structure and job shop structure. To find a minimum number of workstations of assembly line we calculated the balance (RPW method) for 3 different values of cycle time (Table III).

TABLE III: ASSEMBLy LiNE BALANCE RESULTS
\begin{tabular}{|l|c|c|c|}
\hline Cycle c & 10 & 15 & 20 \\
\hline K & 6 & 4 & 3 \\
\hline SI & 3,16 & 4,24 & 2,24 \\
\hline LE $[\%]$ & 90 & 90 & 90 \\
\hline LT & 58 & 57 & 58 \\
\hline
\end{tabular}

As we can notice the value of smoothness index differs for different number of workstations, line efficiency is the same and time of the line is very similar to each other. In the next step we need to find assignment of 4 variants to job shop system which consists of 3 machines. Cycle time value and balance calculations allow us to determine in our complex system release dates $\left(r_{j}\right)$ for a job shop structure and completion times of each product variant. For cycle times 15 and 20 there are no conflicts and therefore dispatch rules are not necessary to find different solutions. The result is only one and is given in Table IV.

TABLE IV: COMPLETION TIMES AND TOTAL COMPLETION TIMES FOR $C=20$ AND $C=15$

\begin{tabular}{|c|c|c|c|c|}
\hline & \multicolumn{2}{|c|}{ Cycle c=20 } & \multicolumn{2}{c|}{ Cycle $\mathrm{c}=15$} \\
\hline variant $j$ & $C_{j}$ & $T_{C j}$ & $C_{j}$ & $T_{C j}$ \\
\hline 1 & 30 & 88 & 30 & 87 \\
\hline 2 & 50 & 108 & 50 & 107 \\
\hline 3 & 65 & 123 & 65 & 122 \\
\hline 4 & 90 & 148 & 75 & 132 \\
\hline
\end{tabular}

where :

$C_{j}$ - completion time of variant $j$ in job shop structure,

$T_{C j}$ - total completion time of variant in whole complex system,

$L T$ - time of line

TABLE V: COMPLETION TIMES AND TOTAL COMPLETION TIMES FOR $C=20$

\begin{tabular}{|c|l|l|l|l|}
\hline Dispatch rule & \multicolumn{4}{|c|}{$c=20$} \\
\hline \multirow{2}{*}{$\mathrm{LPT}$} & $C_{1} / T_{C 1}$ & $C_{2} / T_{C 2}$ & $C_{3} / T_{C 3}$ & $C_{4} / T_{C 4}$ \\
\cline { 2 - 5 } & $30 / 88$ & $60 / 118$ & $40 / 98$ & $70 / 128$ \\
\hline \multirow{2}{*}{$\mathrm{SPT}$} & $C_{1} / T_{C 1}$ & $C_{2} / T_{C 2}$ & $C_{3} / T_{C 3}$ & $C_{4} / T_{C 4}$ \\
\cline { 2 - 5 } & $30 / 88$ & $50 / 108$ & $45 / 103$ & $60 / 118$ \\
\hline \multirow{2}{*}{ FCFS } & $C_{1} / T_{C 1}$ & $C_{2} / T_{C 2}$ & $C_{3} / T_{C 3}$ & $C_{4} / T_{C 4}$ \\
\cline { 2 - 5 } & $30 / 88$ & $50 / 108$ & $45 / 103$ & $60 / 118$ \\
\hline \multirow{2}{*}{ LCFS } & $C_{1} / T_{C 1}$ & $C_{2} / T_{C 2}$ & $C_{3} / T_{C 3}$ & $C_{4} / T_{C 4}$ \\
\cline { 2 - 5 } & $35 / 93$ & $50 / 108$ & $45 / 103$ & $60 / 118$ \\
\hline \multirow{2}{*}{$\mathrm{EDD}$} & $C_{1} / T_{C 1}$ & $C_{2} / T_{C 2}$ & $C_{3} / T_{C 3}$ & $C_{4} / T_{C 4}$ \\
\cline { 2 - 5 } & $30 / 88$ & $50 / 108$ & $45 / 103$ & $60 / 118$ \\
\hline
\end{tabular}

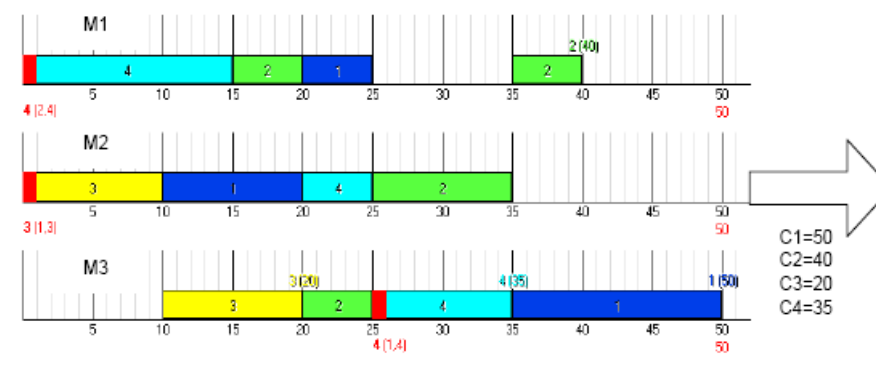

Job shop structure

$$
T_{C j}=L T+C_{j}
$$

When cycle time is equal to10 conflicts occur in job shop scheduling and we get different results which are presented in Table V.

In the second step (Fig. 7) first we manufacture a product in job shop structure and next in assembly line. We consider input data from Table II. The release dates for all variants are equal to zero. The results of job shop scheduling calculations are presented in Table VI.

TABLEVI: COMPLETION TIMES FOR JOB SHOP SCHEDULING

\begin{tabular}{|c|c|c|c|c|c|}
\hline \multirow{2}{*}{$\begin{array}{c}\text { Completion } \\
\text { time }\end{array}$} & \multicolumn{5}{|c|}{ Method } \\
\cline { 2 - 6 } & LPT & SPT & FCFS & LCFS & EDD \\
\hline$C_{1}$ & 45 & 55 & 45 & 50 & 50 \\
\hline$C_{2}$ & 75 & 40 & 35 & 40 & 25 \\
\hline$C_{3}$ & 30 & 30 & 30 & 20 & 20 \\
\hline$C_{4}$ & 55 & 40 & 55 & 35 & 60 \\
\hline
\end{tabular}

As we can notice for LPT, SPT and LCFS methods the smallest difference between completion times of different variants is equal to 10 . For FCFS and EDD methods the smallest difference between completion times of different variants is equal to 5 . These values allow us to determine cycle times for assembly line structure. There are 10 or 7 (not 5 because of the longest processing time), respectively. The final balance of single assembly line is given in Table VII.

TABLE VII: ASSEMBLY LINE BALANCE RESULTS FOR $C=7$ AND $C=10$

\begin{tabular}{|l|c|c|}
\hline Cycle c & 7 & 10 \\
\hline K & 9 & 6 \\
\hline SI & 6,25 & 3,16 \\
\hline LE $[\%]$ & 85,7 & 90 \\
\hline LT & 57 & 58 \\
\hline
\end{tabular}

TABLE VII: TOTAL COMPLETION TIMES FOR JOB SHOP - ASSEMBLY LINE

\begin{tabular}{|c|c|c|c|c|c|}
\hline \multirow{2}{*}{$\begin{array}{c}\text { Total } \\
\text { completion } \\
\text { time }\end{array}$} & LPT & SPT & FCFS & LCFS & EDD \\
\cline { 2 - 6 } & 108 & 115 & 94 & 118 & 112 \\
\hline$T_{C 1}$ & 138 & 101 & 87 & 108 & 84 \\
\hline$T_{C 2}$ & 88 & 87 & 108 & 78 & 77 \\
\hline$T_{C 3}$ & 118 & 108 & 115 & 98 & 119 \\
\hline$T_{C 4}$ & & & & & \\
\hline
\end{tabular}

In the last step we calculate total completion times for all variants and all methods of job shop scheduling to find the final solution of complex system. Table VIII includes the end results. Formula (4) was modified and took into consideration cycle time steps. An example of complex system is shown in Fig. 9.

Fig. 9. An example schedule of tasks for job shop - assembly line structure (LCFS method and RPW heuristic for $c=10$ ). 


\section{CONCLUSIONS AND REMARKS}

Manufacturing systems are present in all companies. It is sometimes very difficult to find the best simple structure and therefore very often mixed and complex structures are implemented. In this paper a job shop structure connected with assembly line is considered. In manufacturing plants production rates change very often and therefore good feasible solutions are welcome. Heuristic methods help to obtain such solutions very quick without time consumption. The article shows a method which allows finding a good schedule of complex system (job shop - assembly line and vice versa). First the assembly line balancing RPW method was used and the balance for found. Heuristic methods solved conflicts in schedule and we got job shop task sequence with completion times of all produced variants. At the end total completion times were calculated. Similarly the vice versa system was considered. To choose the end solution a total completion time, number of stations or smoothness index were taken into account. The result is always a compromise of many factors. The presented results show that the total completion times of different variant don't differ from each other a lot. It can surprise but on other side analysis of final results request a detailed knowledge of studied structures.

\section{ACKNOWLEDGMENT}

This work was supported by Grant BK-214/Rau1/2013.

\section{REFERENCES}

[1] R. J. Sury, "Aspects of assembly line balancing," International Journal of Production Research, vol. 9, pp. 8-14, 1971.

[2] I. Baybars, "A survey of exact algorithms for simple assembly line balancing problem," Management Science, vol. 32, pp. 11-17, 1986.

[3] E. Erel and S. C. Sarin, "A survey of the assembly line balancing procedures," Production Planning and Control, vol. 9, pp. 414-434, 1998.

[4] W. B. Halgeson and D. P. Birnie, "Assembly line balancing using the ranked positional weighting technique," Journal of Industrial Engineering, vol. 12, pp. 18-27, 1961.

[5] M. E. Salveson, "The assembly line balancing problem," Journal of Industrial Engineering, vol. 6, pp. 62-69, 1955.

[6] A. L. Gutjahr and G. L. Neumhauser, "An algorithm for the line balancing problem," Management Science, vol. 11, pp. 308-315, 1964.

[7] A. Scholl and C. Becker, "State-of-the-art exact and heuristic solution procedures for simple assembly line balancing," European Journal of Operation Research, vol. 158, pp. 666-693, 2006.

[8] A. Scholl, Balancing and Sequencing of Assembly Lines, $2^{\text {nd }}$ ed., Physica Verlag Springer Verlag Company, Germany, 1998.

[9] E. A. Süer, "Designing parallel assembly lines," Computer and industrial Engineering, vol. 35, pp. 467-470, 1998.
[10] H. Gökçen, K. Ağpak, and R. Benzer, "Balancing of assembly parallel lines," International Journal of Production Economic, vol. 103, 600-609, 2006.

[11] R. G. Askin and M. Zhou, "A parallel station heuristic for the mixed-model production line balancing problem," International Journal of Production Research, vol. 35, no. 11, pp. 3095-3105. 1997.

[12] J. F. Bard, "Assembly line balancing with parallel workstations and dead time," International Journal of Production Research, vol. 27, no. 6, pp. 1005-1018, 1989

[13] P. Pinto, D. G. Dannenbring, and B. M. Khumawala, "Branch and bound heuristic procedures for assembly line balancing with paralleling of stations," International Journal of Production Research, vol. 19 , no. 4 , pp. $565-576,1981$

[14] J. Bukchin and J. Rubinovitz, "A weighted approach for assembly line design with station paralleling and equipment selection," IIE Transactions, vol. 35, pp. 73 - 85, 2003.

[15] J. J. Bartholdi, "Balancing two-sided assembly lines: a case study," International Journal of Production Research, vol. 23, pp. 403-421, 1993.

[16] K. Y. Kim, W. S. Song, and J. H. Kim, "A mathematical model and a genetic algorithm for two-sided assembly line balancing," Computers and Operations Research 36, pp. 853-865, 2009.

[17] T. O. Lee, Y. Kim, and Y. K. Kim, "Two-Sided assembly line balancing to maximize work relatedness and slackness," Computers \& Industrial Engineering, vol. 40, pp. 273-292, 2001.

[18] A. Baykasoglu and T. Dereli, "Two-Sided assembly line balancing using an ant-colony based heuristic," International Journal of Advanced Manufacturing Technology, vol. 36, pp. 582-588, 2008.

[19] X. Hu, E. Wu, and Y. Jin," A station oriented enumerative algorithm for two-sided assembly line balancing problem," European Journal of Operational Research, vol. 186, pp. 435-440, 2007.

[20] M. L. Pinedo, Scheduling Theory, Algorithm, and Systems, Springer Verlag, $3^{\text {rd }}$ Edition, 2008, ch. 6 and 7, pp. 151-211

[21] S. Ghosh and R. J. Gagnon, "A comprehensive literature review and analysis of the design, balancing and scheduling of assembly lines," International Journal of Production Research, vol. 27, no. 4, pp 637-670, 1989.

[22] A. S. Jain and S. Meeran, "Deterministic job shop scheduling: Past, present and future," European Journal of Operational Research, vol. 113, pp. 390-434, 1999.

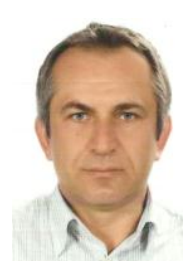

Waldemar Grzechca was born in Gliwice in Poland in 1964. He was graduated at the Silesian University of Technology in 1989 and he started to work at the same time at the Department of Automation Control, Electronics and Computer Science. He focused his research on accuracy of robots trajectories and robots applications in manufacturing companies. Next he has moved his research and interest to manufacturing systems. He studied different structures of machines (sequencing and scheduling in single machine and parallel machines configurations, job shop system, flow shop system, etc.). He is especially interested in assembly lines balancing problem. He investigates different types of lines and focuses on estimation of final results of balance of single and two-sided lines. He is author of more than 70 conference and journal papers which deals with assembly lines problems and an editor of a book titled Assembly Line - Theory and Practice. 